\title{
Adjustable Ghajar Guide Technique for Accurate Placement of Ventricular Catheters : A Pilot Study
}

\author{
Sang-Youl Yoon, M.D., ${ }^{*}$ Youngseok Kwak, M.D., Jaechan Park, M.D., Ph.D. \\ Department of Neurosurgery and Research Center for Neurosurgical Robotic Systems, Kyungpook National University School of Medi- \\ cine, Daegu, Korea
}

Objective : An adjustable Ghajar guide is presented to improve the accuracy of the original Ghajar guide technique. The accuracy of the adjustable Ghajar guide technique is also investigated.

Methods : The coronal adjustment angle from the orthogonal catheter trajectory at Kocher's point is determined based on coronal head images using an electronic picture archiving and communication system. For the adjustable Ghajar guide, a protractor is mounted on a C-shaped basal plate that is placed in contact with the margin of a burrhole, keeping the central $0^{\circ}$ line of the protractor orthogonal to the calvarial surface. A catheter guide, which is moved along the protractor and fixed at the pre-determined adjustment angle, is then used to guide the ventricular catheter into the frontal horn adjacent to the foramen of Monro. The adjustable Ghajar guide technique was applied to 20 patients, while a freehand technique based on the surface anatomy of the head was applied to another 47 patients. The accuracy of the ventricular catheter placement was then evaluated using postoperative computed tomography scans.

Results : For the adjustable Ghajar guide technique (AGT) patients, the bicaudate index ranged from 0.23 to 0.33 (mean \pm standard deviation $[S D]: 0.27 \pm 0.03$ ) and the adjustment angle ranged from $0^{\circ}$ to $10^{\circ}$ (mean $\pm S D: 5.2^{\circ} \pm 3.2^{\circ}$ ). All the AGT patients experienced successful cerebrospinal fluid diversion with only one pass of the catheter. Optimal placement of the ventricular catheter in the ipsilateral frontal horn approximating the foramen of Monro (grade 1) was achieved in 19 patients (95.0\%), while a suboptimal trajectory into a lateral corner of the frontal horn passing along a lateral wall of the frontal horn (grade 3) occurred in 1 patient (5.0\%). Thus, the AGT patients experienced a significantly higher incidence of optimal catheter placement than the freehand catheterized patients $(95.0 \%$ vs. $68.3 \%, p=0.024)$. Moreover, none of the AGT patients experienced any tract hemorrhages along the catheter or procedure-related complications.

Conclusion : The proposed adjustable Ghajar guide technique, using angular adjustment in the coronal plane from the orthogonal trajectory at Kocher's point, facilitates accurate freehand placement of a ventricular catheter for hydrocephalic patients.

Key Words : Catheterization · Cerebral ventricles · Hydrocephalus · Ventriculoperitoneal shunt.

\footnotetext{
- Received : November 17, 2016 •Revised : May 19, 2017 •Accepted : June 13, 2017

- Address for reprints : Jaechan Park, M.D., Ph.D.

Department of Neurosurgery, Kyungpook National University Hospital, 130 Dongdeok-ro, Jung-gu, Daegu 41944, Korea

Tel : +82-53-200-5647, Fax : +82-53-423-0504, E-mail : jparkmd@hotmail.com

${ }^{*}$ Sang-Youl Yoon and Youngseok Kwak contributed equally to this work.
}

This is an Open Access article distributed under the terms of the Creative Commons Attribution Non-Commercial License (http://creativecommons.org/licenses/by-nc/4.0) which permits unrestricted non-commercial use, distribution, and reproduction in any medium, provided the original work is properly cited. 


\section{INTRODUCTION}

Ventriculoperitoneal shunting is a regular neurosurgical procedure for cerebrospinal fluid (CSF) diversion. Yet, while a frameless or frame-based stereotactic technique can be used for accurate placement of the ventricular catheter in patients with smaller ventricles ${ }^{1,3,8,11,22,23)}$, ventricular catheterization for hydrocephalic patients with larger ventricles is still commonly performed freehand based on the surface anatomy of the head or using the Ghajar guide technique ${ }^{4,6,9,11,12,16,24)}$.

The original Ghajar guide technique using an orthogonal catheter guide with a rigid tripod was developed to place the ventricular catheter perpendicular to the calvarium at Kocher's point. This is because the superior aspect of the frontal horn of the lateral ventricle roughly runs parallel to the overlying calvarium on the midpupillary line $e^{7)}$. However, despite an improved accuracy with the Ghajar guide technique over freehand catheter placement ${ }^{14)}$, this accuracy is significantly affected by the calvarial slope. The calvarium is not spherical and slopes downward from the sagittal midline with individual variations. Thus, catheterization orthogonal to the calvarium at Kocher's point does not always lead to an ideal catheter placement in the ipsilateral frontal horn of the lateral ventricle near the foramen of Monro ${ }^{14,18,25)}$.

Accordingly, the authors present an adjustable Ghajar guide to improve the accuracy of the original Ghajar guide technique. The proposed guide places the ventricular catheter along an ideal trajectory using an adjusted angle from the orthogonal trajectory, where the adjusted angle is determined based on coronal head images. The accuracy of the adjustable Ghajar guide is then investigated and compared with freehand catheterization using the surface anatomy of the head.

\section{MATERIALS AND METHODS}

\section{Adjustable Ghajar guide}

Fig. 1 shows the proposed adjustable Ghajar guide used in the present study. A protractor is mounted on a C-shaped basal plate with an inferior sleeve that is loosely fitted in a frontal burrhole and rotates for positioning in the coronal plane. The basal plate, which is placed in contact with the margin of the burrhole, keeps the central $0^{\circ}$ line of the protractor orthogonal to the calvarial surface and corresponds to a chord of a circle. The catheter guide perpendicular to the basal plate follows a trajectory perpendicular to the calvarial circle. The ventricular catheter is then inserted into a semitubular catheter guide, which is moved along the protractor and fixed using a fixation knob at a pre-determined angle based on coronal head images.

\section{Determination of adjustment angle using coronal head images}

The coronal adjustment angle from the orthogonal catheter trajectory at Kocher's point is determined based on a radiographic simulation of the orthogonal catheter trajectory using coronal head images, as previously reported by the current authors ${ }^{15)}$. This is simulated on coronal computed tomography (CT) images reconstructed from axial head imaging or coronal T2-weighted magnetic resonance image (MRI) using PiViewSTAR ${ }^{\mathrm{TM}}$ (INFINITT Co., Ltd., Seoul, Korea), a picture archiving and communication system (PACS) that integrates simple measurement tools (e.g., distance and angle measurements).

On a coronal image at or around the foramen of Monro, a burrhole site is marked at a point $3 \mathrm{~cm}$ lateral to the midline of the skull (Fig. 2A). On a circular line outlining the calvarial surface, an approximately $3 \mathrm{~cm}$-long chord is drawn with both ends equidistant from the burrhole site (Fig. 2B). A perpen-

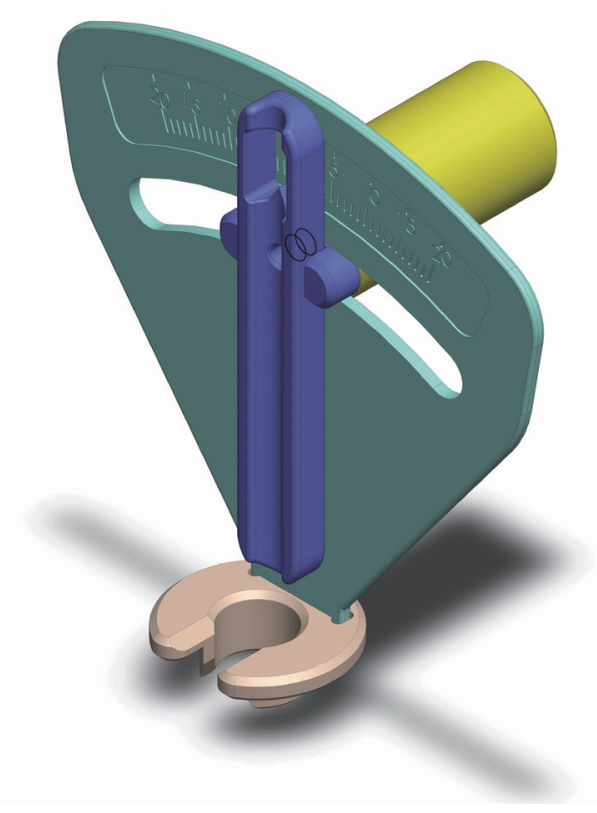

Fig. 1. Illustration of the adjustable Ghajar guide. 

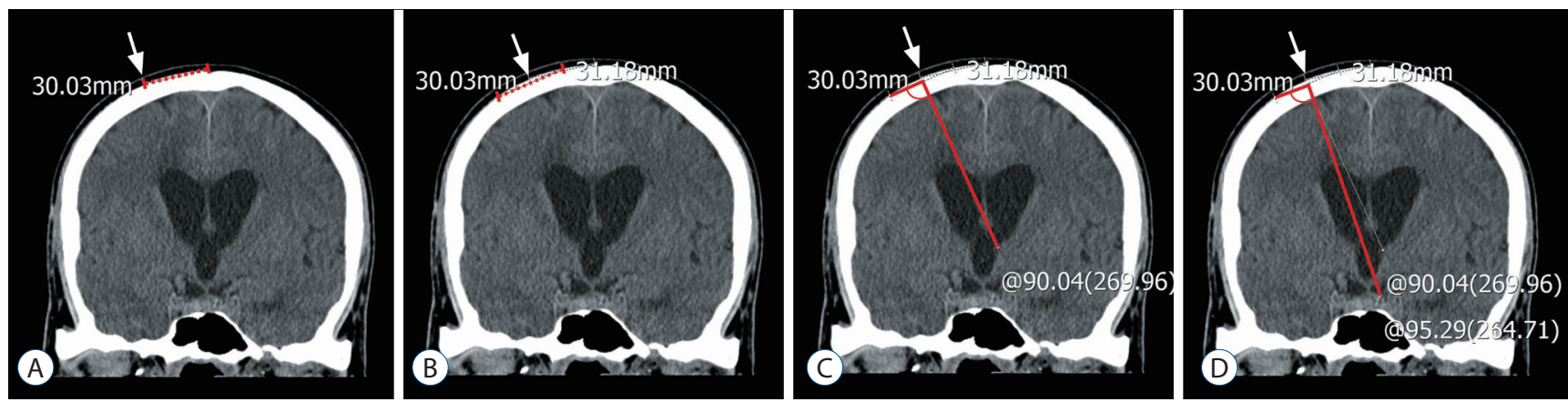

Fig. 2. Coronal computed tomography images showing the radiographic simulation of the catheter trajectories to determine the adjustment angle for the adjustable Ghajar guide technique. A : A burrhole site (arrow) is marked at a point $3 \mathrm{~cm}$ lateral to the midline of the skull. B : An approximately $3 \mathrm{~cm}$ long chord (red line) is drawn with both ends equidistant from the burrhole site on the circular line outlining the calvarial surface. C: A perpendicular line starting at the middle of the chord is drawn to the ventricular system. D : The ideal catheter trajectory toward the foramen of Monro is drawn from the middle of the chord. The adjustment angle, the difference between the catheter trajectory $\left(90^{\circ}\right)$ perpendicular to the calvarial surface and the ideal catheter trajectory $\left(95^{\circ}\right)$, is $5^{\circ}$.

dicular line starting at the middle of the chord is then drawn to the ventricular system, corresponding to a catheter trajectory orthogonal to the calvarial surface (Fig. 2C). Thereafter, the ideal catheter trajectory toward the foramen of Monro is drawn from the middle of the chord (Fig. 2D). Finally, the angle between the ideal trajectory and the perpendicular trajectory is measured as the adjustment angle.

\section{Operative technique}

With the patient in a supine position and their head turned to the side, a burrhole is drilled $3 \mathrm{~cm}$ lateral to the sagittal midline and $1 \mathrm{~cm}$ anterior to the coronal suture. Next, the catheter guide of the adjustable Ghajar guide is moved along the protractor and fixed using the pre-determined adjustment angle. The inferior sleeve of the adjustable Ghajar guide is then placed in the burrhole with the basal plate in contact with the circular margin of the burrhole and the protractor parallel to the coronal plane (Fig. 3).

Thereafter, the ventricular catheter is inserted into the catheter guide to puncture the ventricle. After inserting the catheter $6 \mathrm{~cm}$ into the dura, the remaining procedures are performed as usual ${ }^{4,6,16)}$.

\section{Patient population}

Between October 2014 and December 2015, the adjustable Ghajar guide technique was applied to 20 patients and prospective data collected on the operative procedures (adjusted angle of catheterization from orthogonal trajectory, number of catheter passes) and postoperative CT. Based on the post-

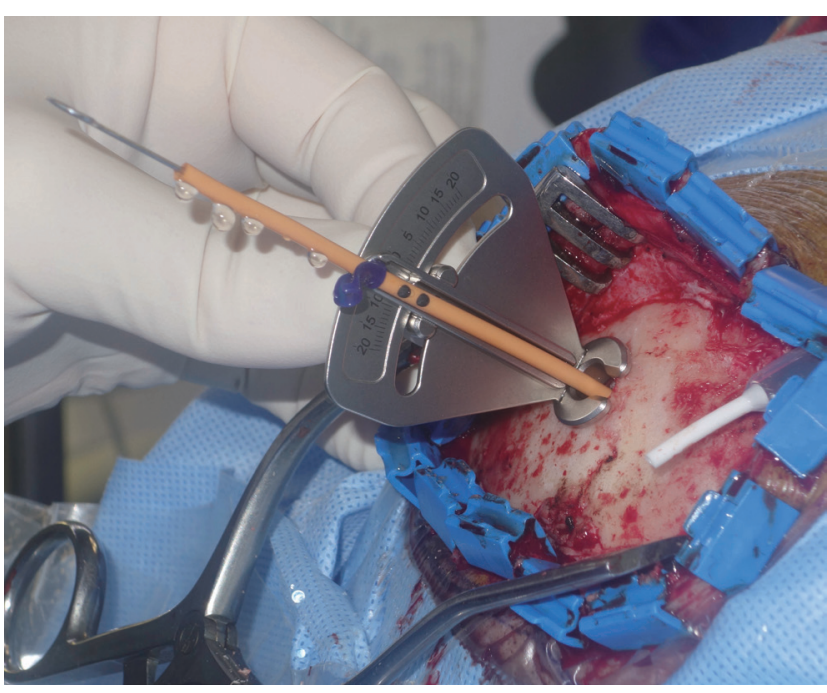

Fig 3. Intraoperative photograph showing the adjustable Ghajar guide used for the ventriculoperitoneal shunt.

operative CT scans, the accuracy of the ventricular catheter placement was compared with cases of freehand catheterization $(\mathrm{n}=41)$ at the same institution.

The inclusion criteria for this study were as follows : 1) age $>20$ years, 2) diagnosis of hydrocephalus, 3) treatment with ventriculoperitoneal shunting using the adjustable Ghajar guide technique or freehand catheterization based on the surface anatomy of the head, and 4) available preoperative and postoperative CT or MRI of the head. The exclusion criteria were as follows : 1) midline brain shift, 2) compressed or distorted frontal horn of the lateral ventricle, or 3) ventriculoperitoneal shunt placement using a neuronavigation system. The study was reviewed and approved by the authors' institu- 
tional ethics committee.

\section{Outcome evaluation}

The accuracy of the ventricular catheter placement was evaluated using postoperative CT scans based on the following grading system. Grade 1 represented an optimal catheter trajectory into the ipsilateral frontal horn approximating the foramen of Monro. Grade 2 represented medial deviation of the catheter leading to a suboptimal catheter trajectory into the contralateral frontal horn or a lateral ventricle. Grade 3 represented lateral deviation of the catheter, including a suboptimal trajectory into a third ventricle through an ipsilateral caudate nucleus or trajectory into a lateral corner of the frontal horn along a lateral wall of the frontal horn. Grade 4 represented extraventricular catheterization. For the patients who experienced ventriculoperitonel shunting, prospective data were collected, including the adjusted angle applied, number of catheter placement passes, and postoperative CT evaluation.

\section{Statistical analysis}

The statistical analyses were performed using an SPSS software package (version 19.0; IBM Corp., Armonk, NY, USA). The data in this report are presented as the means \pm standard deviations (SD). To compare the adjustable Ghajar guide technique and freehand catheterized patient groups, Fisher's exact test was used to determine the accuracy of the ventricular catheter placement, while a t-test was used for the bicaudate index. The results were considered significant for probability values less than 0.05 .

\section{RESULTS}

\section{Patients}

The adjustable Ghajar guide technique patients $(n=20)$ consisted of 8 men and 12 women with a mean age of $63.7 \pm 15.2$ years (range, 21-81 years), and their bicaudate index ranged from 0.23 to 0.33 (mean $\pm S D$ : $0.27 \pm 0.03$ ). Meanwhile, the freehand catheterized patients $(n=41)$ consisted of 20 men and 21 women with a mean age of $67.5 \pm 12.4$ years (range, $22-80$ years), and their bicaudate index ranged from 0.23 to 0.43 (mean \pm SD : $0.3 \pm 0.04$ ), which was significantly larger than that for the adjustable Ghajar guide technique patients $(p=0.019)$.

\section{Outcomes}

For the freehand catheterized patients, the postoperative CT scans revealed optimal placement of the ventricular catheter in the ipsilateral frontal horn approximating the foramen of Monro (grade 1) in 28 patients (68.3\%) and suboptimal catheter placement of grade 2 in 6 patients (14.6\%) and grade 3 in 7 patients (17.1\%). In addition, there was one case of intracerebral hemorrhage with a volume of $30 \mathrm{~mL}$ along the catheter trajectory.

Meanwhile, for the adjustable Ghajar guide technique patients, the adjustment angle ranged from $0^{\circ}$ to $10^{\circ}$ (mean \pm SD : $\left.5.2^{\circ} \pm 3.2^{\circ}\right)$. In the case of 3 patients, the original orthogonal trajectory was used, however, for the other 17 patients, the catheter trajectory was realigned laterally from the orthogonal trajectory with an adjusted angle ranging from $2^{\circ}$ to $10^{\circ}$.

All the adjustable Ghajar guide technique patients experienced successful CSF diversion with only one pass of the catheter. Plus, the postoperative CT scans revealed optimal placement of the ventricular catheter in the ipsilateral frontal horn approximating the foramen of Monro (grade 1) in 19 patients $(95.0 \%)$ and a suboptimal trajectory into a lateral corner of the frontal horn passing along a lateral wall of the frontal horn (grade 3) in only 1 patient (5.0\%). Thus, the adjustable Ghajar guide technique patients showed a significantly higher incidence of grade 1 optimal catheter placement when compared with the freehand catheterized patients $(95.0 \%$ vs. $68.3 \%$, $p=0.024$ ), even though the bicaudate index was lower for the adjustable Ghajar guide technique patients. Moreover, none of the adjustable Ghajar guide technique patients experienced any tract hemorrhages along the catheter or procedure-related complications.

\section{DISCUSSION}

To place a ventricular catheter into a small ventricle as in cases of idiopathic intracranial hypertension, stereotactic neuronavigation is known to be the most accurate and reliable method $^{5,11,26)}$. It is thus commonly used for small or distorted ventricles at the authors' institute.

Meanwhile, for hydrocephalic patients with a large ventricle, freehand catheterization by an experienced surgeon, freehand 
catheterization using a special device indicating external anatomical landmarks, the proposed adjustable Ghajar guide technique, stereotactic neuronavigation have all been shown to achieve high accuracy of ventricular catheterization with an incidence of optimal catheterization $>90 \%{ }^{2,13,18}$, whereas freehand catheterization by an inexperienced surgeon invariably results in unsatisfactory accuracy of ventricular catheterization. Jung and $\mathrm{Kim}^{10)}$ previously reported $93 \%$ optimal ventricular catheterization when using an electromagnetic navigation system, while the proposed adjustable Ghajar guide technique achieved $95 \%$ optimal catheterization.

In the present study, the proposed adjustable Ghajar guide technique was compared with freehand catheterization using external anatomical landmarks as the standard method of ventriculostomy catheter placement. The incidence of optimal catheter placement in the ipsilateral frontal horn with freehand catheterization was previously reported at $56.1 \%$ by Huyette et al. ${ }^{9}$, and was $68.3 \%$ in the current series. Meanwhile, the incidence of optimal catheter placement with the proposed adjustable Ghajar guide technique was much higher at $95.0 \%$ in the current series. A similar technique for adjusting the orthogonal trajectory is currently being investigated with a prospective, randomized, two-armed, multicenter trial by Schaumann and Thomale ${ }^{20)}$, where the objective of their study is to prove the superiority of a guided technique over freehand catheterization in terms of the catheter placement.

The technique of Schaumann and Thomale ${ }^{20)}$ uses a catheter guide and special smartphone software to achieve optimal ventricular catheterization ${ }^{21)}$. However, the proposed adjustable Ghajar guide technique has the following differences and advantages : 1) the adjustment angle is measured using a universally available PACS, allowing easy and wide application; 2 ) the proposed adjustable Ghajar guide has a unique design. The orthogonal trajectory is determined using a basal plate placed in a round burrhole, and the large protractor attached to the basal plate allows easy reading of the angle scale and easy alignment of the catheter guide.

While stereotactic neuronavigation is routinely used by neurosurgeons for navigating difficult intracranial lesions, it is not the only method that can achieve optimal ventricular catheterization in hydrocephalic patients. Moreover, the cost and size of the equipment used for stereotactic neuronavigation and the increased time in the operating room can be limiting ${ }^{1726)}$. Thus, the global need for cost-effective innovation is given in neurosurgery. The proposed adjustable Ghajar guide technique can be a simple and inexpensive method for an accurate ventriculostomy.

The proposed adjustable Ghajar guide technique was developed based on a previous radiographic simulation study of catheter trajectories by the current authors ${ }^{15)}$, which revealed that the accuracy of the original Ghajar guide technique is affected by the calvarial slope lateral to the sagittal midline with individual variation, making it suboptimal for guiding the ventricular catheter trajectory into the frontal horn of the lateral ventricle near the foramen of Monro. The radiographic simulation of orthogonal catheter placement resulted in $70.2 \%$ optimal catheter placement in the ipsilateral frontal horn and $29.8 \%$ suboptimal placement in the contralateral frontal horn.

In the present study, the proposed adjustable Ghajar guide technique was used for hydrocephalic patients without a midline brain shift. Notwithstanding, the adjustable Ghajar guide technique would also be particularly useful for placing a ventricular catheter in the case of hydrocephalic patients with a midline brain shift or distorted frontal horn of the lateral ventricle as the catheter trajectory can be adjusted according to the CT findings.

In a recent US survey of surgical techniques for ventricular catheter placement in patients with slit ventricles, the Ghajar guide technique was only used by $6.7 \%$ of the respondents, while the remaining respondents used a freehand technique or image guidance ${ }^{19)}$. This low popularity of the Ghajar guide technique may be due to the following reasons : 1) low accuracy of the Ghajar guide technique, 2) deficiency of an adjustment function of the orthogonal trajectory, and 3) low market availability of the Ghajar guide.

The current study has a few important limitations. First, it was only based on a small series from a single institution. Second, the advantage of the proposed technique in patients with a midline brain shift was not considered. Third, the results of the current study warrant a future multi-center study including a comparison with the original Ghajar guide technique and stereotactic neuronavigation.

\section{CONCLUSION}

The proposed adjustable Ghajar guide technique, using an 
angular adjustment in the coronal plane from the orthogonal trajectory at Kocher's point, facilitates accurate placement of a ventricular catheter for hydrocephalic patients.

\section{- Acknowledgements}

Dr. Park is the inventor of the adjustable Ghajar guide. The authors report no other potemtial conflict of interest concerning the materials or methods used in this study or the findings specified in this paper.

\section{References}

1. Abu-Serieh B, Ghassempour K, Duprez T, Raftopoulos C : Stereotactic ventriculoperitoneal shunting for refractory idiopathic intracranial hypertension. Neurosurgery 60 : 1039-1043; discussion 1043-1044, 2007

2. Ann JM, Bae HG, Oh JS, Yoon SM : Device for catheter placement of external ventricular drain. J Korean Neurosurg Soc 59 : 322-324, 2016

3. Azeem SS, Origitano TC : Ventricular catheter placement with a frameless neuronavigational system: a 1-year experience. Neurosurgery 60(4 Suppl 2) : 243-247; discussion 247-248, 2007

4. Bergsneider $M$, Stiner $E$ : Management of adult hydrocephalus: Shunting, in Winn HR (ed) : Youmans Neurological Surgery, ed 6. Philadelphia : Saunders, 2011, Vol 1, pp515-524

5. Clark S, Sangra M, Hayhurst C, Kandasamy J, Jenkinson M, Lee M, et al. : The use of noninvasive electromagnetic neuronavigation for slit ventricle syndrome and complex hydrocephalus in a pediatric population. J Neurosurg Pediatr 2 : 430-434, 2008

6. Epstein $M H$, Duncan JA : Surgical management of hydrocephalus in adults, in Schmidek HH (ed) : Schmidek \& Sweet Operative Neurosurgical Techniques: Indications, Methods, and Results, ed 4. Philadelphia : Saunders, 2000, Vol 1, pp595-603

7. Ghajar JB : A guide for ventricular catheter placement. Technical note. J Neurosurg 63 : 985-986, 1985

8. Gil Z, Siomin V, Beni-Adani L, Sira B, Constantini S : Ventricular catheter placement in children with hydrocephalus and small ventricles: the use of a frameless neuronavigation system. Childs Nerv Syst $18: 26-29$, 2002

9. Huyette DR, Turnbow BJ, Kaufman C, Vaslow DF, Whiting BB, Oh MY : Accuracy of the freehand pass technique for ventriculostomy catheter placement: retrospective assessment using computed tomography scans. J Neurosurg $108: 88-91,2008$

10. Jung $N$, Kim D : Effect of electromagnetic navigated ventriculoperitoneal shunt placement on failure rates. J Korean Neurosurg Soc 53 : 150154, 2013

11. Kandasamy J, Hayhurst C, Clark S, Jenkinson MD, Byrne P, Karabatsou K, et al. : Electromagnetic stereotactic ventriculoperitoneal csf shunting for idiopathic intracranial hypertension: a successful step forward? World Neurosurg 75 : 155-160; discussion 32-33, 2011
12. Lind CR, Correia JA, Law AJ, Kejriwal R: A survey of surgical techniques for catheterising the cerebral lateral ventricles. J Clin Neurosci 15 : 886-890, 2008

13. Moran D, Kosztowski TA, Jusué-Torres I, Orkoulas-Razis D, Ward A, Carson $\mathrm{K}$, et al. : Does $\mathrm{CT}$ wand guidance improve shunt placement in patients with hydrocephalus? Clin Neurol Neurosurg 132 : 26-30, 2015

14. O'Leary ST, Kole MK, Hoover DA, Hysell SE, Thomas A, Shaffrey Cl : Efficacy of the Ghajar Guide revisited: a prospective study. J Neurosurg $92: 801-803,2000$

15. Park J, Son W, Park KS, Kim MY, Lee J : Calvarial slope affecting accuracy of Ghajar Guide technique for ventricular catheter placement. J Neurosurg $124:$ 1429-1433, 2016

16. Piatt JH : Hydrocephalus: Treatment, in Wilkins RH, Rengachary SS (eds) : Neurosurgery, ed 2. New York: McGraw-Hill, 1996, Vol 3, pp36333643

17. Ravindra VM, Kraus KL, Riva-Cambrin JK, Kestle JR : The need for costeffective neurosurgical innovation--a global surgery initiative. World Neurosurg 84 : 1458-1461, 2015

18. Rehman T, Rehman Au, Ali R, Rehman A, Bashir H, Ahmed Bhimani S, et al. : A radiographic analysis of ventricular trajectories. World Neurosurg $80: 173-178,2013$

19. Rehman T, Rehman AU, Rehman A, Bashir HH, Ali R, Bhimani SA, et al. A US-based survey on ventriculostomy practices. Clin Neurol Neurosurg $114: 651-654,2012$

20. Schaumann A, Thomale UW : Guided application of ventricular catheters (GAVCA)--multicentre study to compare the ventricular catheter position after use of a catheter guide versus freehand application: study protocol for a randomised trail. Trials $14: 428,2013$

21. Thomale UW, Knitter T, Schaumann A, Ahmadi SA, Ziegler P, Schulz M, et al. : Smartphone-assisted guide for the placement of ventricular catheters. Childs Nerv Syst 29 : 131-139, 2013

22. Wilson TJ, Stetler WR Jr, Al-Holou WN, Sullivan SE : Comparison of the accuracy of ventricular catheter placement using freehand placement, ultrasonic guidance, and stereotactic neuronavigation. J Neurosurg $119: 66-70,2013$

23. Woerdeman PA, Willems PW, Han KS, Hanlo PW, Berkelbach van der Sprenkel JW : Frameless stereotactic placement of ventriculoperitoneal shunts in undersized ventricles: a simple modification to free-hand procedures. Br J Neurosurg 19 : 484-487, 2005

24. Woo H, Kang DH, Park J : Preoperative determination of ventriculostomy trajectory in ventriculoperitoneal shunt surgery using a simple modification of the standard coronal MRI. J Clin Neurosci 20 : 1754-1758, 2013

25. Yamada SM, Yamada S, Goto Y, Nakaguchi H, Murakami M, Hoya K, et al. : A simple and consistent technique for ventricular catheter insertion using a tripod. Clin Neurol Neurosurg 114 : 622-666, 2012

26. Yim B, Reid Gooch M, Dalfino JC, Adamo MA, Kenning TJ : Optimizing ventriculoperitoneal shunt placement in the treatment of idiopathic intracranial hypertension: an analysis of neuroendoscopy, frameless stereotaxy, and intraoperative CT. Neurosurg Focus 40 : E12, 2016 